\title{
Identificação de três espécies de Candida por PCR em tempo real
}

\author{
Alessandra Koehler ${ }^{1}$ \\ Danieli Rosane Dallemole ${ }^{2}$ \\ Lucas Brixner Riça ${ }^{1}$ \\ Valeriano Antonio Corbellini ${ }^{3}$ \\ Alexandre Rieger ${ }^{4}$
}

\section{RESUMO}

Infecções causadas por leveduras do gênero Candida são muito prevalentes. A correta identificação da espécie é uma etapa fundamental para a escolha do tratamento adequado, mas os métodos tradicionais apresentam limitações. Assim, o objetivo do presente trabalho foi padronizar uma reação de PCR em tempo real (qPCR) para identificação de Candida albicans, $C$. glabrata e $C$. parapsilosis, que é uma técnica mais rápida para o diagnóstico. As amostras utilizadas consistiram em DNA extraído de cepas padrão. Realizou-se uma qPCR com SybrGreen ${ }^{\circledR}$ e diluições seriadas das amostras, com as mesmas condições do trabalho em que foram descritos os primers utilizados. Nesse ensaio os resultados foram satisfatórios apenas para $C$. parapsilosis, pois em $C$. albicans e $C$. glabrata, apesar de ocorrer a amplificação da sequência alvo, houve formação de produtos inespecíficos nas reações. Foi feita então uma análise in silico dos primers, que sugeriu não haver problemas significativos em sua construção, contudo encontrou-se alguns problemas de especificidade para $C$. parapsilosis e $C$. glabrata. Conclui-se que são necessários estudos posteriores para desenvolvimento e validação de novos primers que mostrem maior sensibilidade e especificidade para as espécies patogênicas.

Palavras-chave: Candida spp. PCR em tempo real. Análise in silico.

\begin{abstract}
Infections caused by yeasts of the genus Candida are very prevalent. The proper identification of the species is a crucial step in choosing therapy, but the traditional methods have limitations. Therefore, the aim of this study was to standardize a real-time PCR (qPCR) assay for the identification of Candida albicans, C. glabrata and C. parapsilosis, being this a rapid technique for the diagnosis. The samples consisted of extracted DNA from standard strains. We performed a qPCR using SybrGreen ${ }^{\circledR}$ and serial diluted samples and under the same conditions of the study in which the primers were described. In this assay, the results were satisfactory only for $C$. parapsilosis, because for $C$. albicans and $C$. glabrata despite it have occurred the amplification of the target sequence, unspecific products formed in the reactions. An in silico analysis indicated that there were no significant problems with the constructed primers, however it was found some specificity issues for C. parapsilosis and C. glabrata. We concluded that further studies are necessary for the development and validation of new primers with higher sensibility and specificity to the pathogenic species.
\end{abstract}

Keywords: Candida spp. Real time PCR. In silico analysis.

\footnotetext{
${ }^{1}$ Alunos do Curso de Ciências Biológicas da Universidade de Santa Cruz do Sul -UNISC.

${ }^{2}$ Técnica do Laboratório de Histologia e Patologia da Universidade de Santa Cruz do Sul.

${ }^{3}$ Professor do Departamento de Química e Física na Universidade de Santa Cruz do Sul.

${ }^{4}$ Professor do Departamento de Biologia e Farmácia na Universidade de Santa Cruz do Sul. <rieger@unisc.br>
} 


\section{INTRODUÇÃ̃}

Leveduras do gênero Candida fazem parte da microbiota natural em humanos, ocorrendo principalmente na pele e mucosas. Assim, qualquer desequilíbrio nos mecanismos de defesa podem tornar esses microrganismos patogênicos. As infecções geniturinárias são as mais relatadas no caso de Candida spp., entretanto também pode ocorrer a candidemia, decorrente da presença dessas leveduras na corrente sanguínea. Apesar da maior parte das infecções serem causadas por $C$. albicans, outras espécies, como $C$. glabrata e $C$. parapsilosis, também possuem importância médica significativa. A correta identificação da espécie é uma etapa fundamental para o tratamento, uma vez que disso decorre a escolha do medicamento, a dose e o tempo de uso.

Para o diagnóstico das infecções causadas por Candida spp. o método mais utilizado é o crescimento em diferentes meios de cultura para posterior identificação dos patógenos. Porém, essa técnica apresenta limitações, como a demora na obtenção dos resultados, a contaminação da amostra e do cultivo, além da necessidade de pessoal capacitado para a identificação. Assim, novos métodos de diagnóstico estão sendo desenvolvidos, entre eles a qPCR. A qPCR possui diversas vantagens, entre elas o menor risco de contaminação e a possibilidade de obtenção de resultados qualitativos e quantitativos em até 3 horas. Dessa forma, o objetivo do presente estudo foi testar um método de diagnóstico de três espécies de Candida baseado em qPCR.

\section{FUNDAMENTAÇÃO TEORICA}

Em 1923, Berkhout caracterizou as leveduras da família Saccharomycetidae, inserindo-as em um novo gênero, o gênero Candida (BARNETT, 2004; MYCOBANK, 2016). Leveduras do gênero Candida são comumente encontradas em amostras biológicas humanas, uma vez que fazem parte da microbiota natural, colonizando principalmente a pele e as mucosas (FISHER et al., 2011; CDC, 2016a). Após a descoberta do gênero, mais de 20 espécies foram relacionadas com infecções orofaríngeas, geniturinárias e candidemia (especialmente em pacientes imunodeprimidos). Dentre as espécies patogênicas, Candida albicans apresenta-se como a mais frequente (CDC, 2016a).

Os sintomas decorrentes da infecção por Candida spp. dependem do local afetado. As que ocorrem no trato urinário podem ser assintomáticas e a descoberta da infecção acontece após exames de rotina. No entanto, alguns indivíduos podem apresentar cistites e 
pielonefrites, associadas à febre e formação de "bolas de fungos" (fungus balls) ao longo do sistema urinário (PAPAS et al., 2009). Quando a infecção ocorre nos órgãos genitais pode surgir prurido e ardência genital, concomitante com corrimento vaginal no sexo feminino, enquanto que em homens podem ocorrer erupções cutâneas no pênis. Porém, esses sintomas não são exclusivos para infecções por Candida spp. (CDC, 2016b), portanto sempre deve ser efetuada uma investigação clínica e laboratorial.

O controle da infecção é realizado com a utilização de antifúngicos, contudo a eficiência do tratamento depende da correta identificação da espécie, uma vez que existem genes e mecanismos de resistência (processos envolvidos na proteção da integridade celular ligados a vias de sinalização e resposta ao estresse) diferentes entre elas (KOŁACZKOWSKA, KOŁACZKOWSKI, 2016). Dessa forma, a identificação da espécie é uma etapa importante para a escolha do medicamento, da dose adequada e a duração do tratamento (GUIVER, LEVI, OPPENHEIM, 2001).

Os primeiros testes para elucidação das espécies (ou gênero) de leveduras envolvidas em tais infecções eram baseados nas singularidades do crescimento de colônias quando em meio de cultivo, filamentação em cultivo em lâmina, diferenciação do crescimento do tubo germinativo, além de teste de assimilação de fontes de carbono e nitrogênio (auxonograma) e de fermentação de carboidratos (ziminograma) (ANVISA, 2016; SKINNER, FLETCHER, 1960). Atualmente, esses testes ainda são utilizados, contudo a maioria permite apenas a identificação do gênero e possui baixa sensibilidade, além de risco de contaminação das culturas (ANVISA, 2016; KWEON et al., 2015).

Em 1994, Odds e Bernaerts, na tentativa de encontrar um teste adequado para a detecção e que fosse de ampla utilização, testaram e validaram o meio de cultivo CHROMagar Candida desenvolvido pela empresa CHROMagar Company (Paris, França). Com o CHROMagar Candida foi possível diferenciar, com base na coloração e morfologia das colônias, as espécies C. albicans, C. krusei e C. tropicalis provenientes de diferentes amostras biológicas, incluindo amostras de sangue (sem interferência do pigmento heme presente nas hemácias), após $48 \mathrm{~h}$ de incubação a $37^{\circ} \mathrm{C}$ (ODDS, BERNAERTS, 1994; HORVATH et al., 2003). Apesar de ser uma alternativa para diagnóstico diferencial de tais leveduras, o método possui o ônus de necessitar de pessoal capacitado na interpretação dos resultados, além de não excluir a utilização de testes complementares para identificação das espécies, incluindo outros meios contendo substratos cromogênicos (ODDS, BERNAERTS, 1994; OZCAN et al., 2010; GUZEL et al., 2011). 
Com a necessidade de rapidez no diagnóstico e reconhecimento das espécies de Candida, aliada com o surgimento de novas tecnologias de biologia molecular, pesquisadores desenvolveram um novo método de identificação de amplo espectro, aplicado diretamente em amostras clínicas, com alta especificidade e sensibilidade (GUIVER, LEVI, OPPENHEIM, 2001; NEMCOVA et al., 2015; THAN et al., 2015; OGATA et al., 2015). O método é baseado na Reação em Cadeia da Polimerase (PCR), onde a DNA-polimerase sintetiza fragmentos de DNA após a hibridização de sequências específicas (primers). A detecção da amplificação dos fragmentos alvo ocorre pela emissão de sinais fluorescentes, em tempo real, oriundos de sondas com fluoróforos $\left(\right.$ TaqMan $^{\circledR}$ ) ou de fluoróforos intercalantes de DNA fita dupla (SybrGreen ${ }^{\circledR}$ ) ao longo dos ciclos (real time PCR ou qPCR).

O presente estudo foi baseado na metodologia de Guiver, Levi e Oppenheim (2001), autores de um dos primeiros trabalhos a desenvolver o ensaio de qPCR para identificação de diferentes espécies do gênero Candida. Entretanto, diferentemente do trabalho original, não foram utilizadas as sondas com fluoróforos $\left(\operatorname{TaqMan}^{\circledR}\right)$. Recentemente, Lutz et al. (2013) utilizaram os mesmos primers e a sonda TaqMan ${ }^{\circledR}$ para identificação de C. albicans, encontrando problemas de especificidade nas reações. Assim, objetivou-se identificar três espécies de Candida (C. albicans, C. glabrata e C. parapsilosis) utilizando qPCR, porém sem o uso de sonda TaqMan ${ }^{\circledR}$, o que reduz consideravelmente o custo das reações, facilitando a aplicação da metodologia na rotina clínica.

\section{MATERIAIS E MÉTODOS}

\subsection{Amostras}

Foram utilizadas amostras de DNA armazenadas a $-20^{\circ} \mathrm{C}$ e cedidas por Lutz et al. (2013). Estas amostras foram obtidas de cepas padrão de espécies de Candida depositadas junto à Coleção de Microrganismos de Microbiologia Industrial (CMMI) da UNISC. A extração de DNA seguiu o protocolo in house adaptado de Burke, Dawson e Stearns (2000). As cepas utilizadas foram as seguintes: $C$. albicans (NEWP 0031), C. glabrata (ATCC 2001) e C. parapsilosis (ATCC 22019). As amostras de DNA foram quantificadas no fluorímetro Qubit $^{\circledR} 3.0$ (Thermo Fisher Scientific $^{\circledR}$ ). 


\title{
3.2 PCR em tempo real
}

Para a realização da qPCR utilizou-se o equipamento DTprime (DT-96) Real-time Detection Thermal Cycler (DNA-Technology ${ }^{\circledR}$ ). Os conjuntos de primers utilizados foram descritos por Guiver, Levi e Oppenheim (2001) e amplificam a região espaçadora transcrita interna variável (ITS2) de cada espécie (Tabela 1).

\section{Tabela 1 - Sequência dos primers utilizados}

\author{
Espécie \\ Sequência dos primers \\ Senso: 5'-GGGTTTGCTTGAAAGACGGTA-3' \\ C. albicans \\ Antisenso: 5'-TTGAAGATATACGTGGTGGACGTTA-3' \\ Senso: 5'-TTTCTCCTGCCTGCGCTTAA-3' \\ C. glabrata \\ Antisenso: 5'-ACGCACACTCCCAGGTCTTT-3' \\ Senso: 5'-GGGTTTGGTGTTGAGCGATAC-3' \\ C. parapsilosis \\ Antisenso: 5'-GGAGTTTGTACCAATGAGTGGAAA-3'
}

A reação de qPCR foi feita nas mesmas condições estabelecidas por Lutz et al. (2013), contudo sem a utilização de sondas Taqman ${ }^{\circledR}$. Para determinar a sensibilidade e eficiência da reação, foi realizada uma qPCR com diluições seriadas $(1 / 8,1 / 64,1 / 512$ e 1/4096), partindo das amostras iniciais de cada espécie, as quais continham as seguintes concentrações: 4,24 ng/ $\mu \mathrm{L}$ para $C$. albicans, $2,76 \mathrm{ng} / \mu \mathrm{L}$ para $C$. glabrata e $1,97 \mathrm{ng} / \mu \mathrm{L}$ para $C$. parapsilosis. Na reação foram utilizados $4 \mu \mathrm{L}$ de $5 \mathrm{X}$ Hot FIREPol ${ }^{\circledR}$ EvaGreen ${ }^{\circledR}$ qPCR Mix (Solis BioDyne $^{\odot}$ ), 0,2 $\mu \mathrm{M}$ do primer senso, 0,2 $\mu \mathrm{M}$ do primer antisenso e $5 \mu \mathrm{L}$ de amostra, totalizando $20 \mu \mathrm{L}$ de reação. As condições da amplificação foram um ciclo de 15 minutos a $95^{\circ} \mathrm{C}$, seguido de 40 ciclos a $95^{\circ} \mathrm{C}$ por 15 segundos, $60^{\circ} \mathrm{C}$ por 20 segundos e $72^{\circ} \mathrm{C}$ por 20 segundos. Após, as curvas de melting foram geradas por 100 ciclos com variação de temperatura no intervalo de $90^{\circ} \mathrm{C} \mathrm{a} 40^{\circ} \mathrm{C}$ por 15 segundos.

A eficiência dos três diferentes conjuntos de primers também foi testada. Para isso, foram preparadas reações de qPCR com as mesmas condições descritas anteriormente, porém com concentrações diferentes de primers $(0,4 \mu \mathrm{M}, 0,6 \mu \mathrm{M}$ e $0,8 \mu \mathrm{M})$. Os resultados foram confirmados por eletroforese em gel de agarose $2 \%$ com brometo de etídio, analisado em transiluminador. 


\subsection{Análises in silico das sequências dos primers e amplicons}

O teste de especificidade dos primers foi executado no software online PrimerBLAST (http://www.ncbi.nlm.nih.gov/tools/primer-blast/) utilizando as sequências depositadas na base de dados GenBank (http://www.ncbi.nlm.nih.gov/genbank/). A formação de hetero-dímeros e hairpins foi analisada com o software OligoAnalyzer 3.1 (https://www.idtdna.com/calc/analyzer). Além disso, foram geradas curvas de dissociação teóricas para cada espécie utilizando o software uMelt ${ }^{\mathrm{SM}}$ (https://dna.utah.edu/umelt/umelt.html), descrito por Dwight, Palais e Wittwer (2011). As curvas foram preditas baseando-se nas sequências dos amplicons esperados e comparadas com aquelas obtidas na qPCR. Os amplicons teóricos foram encontrados pela pesquisa das sequências alvo na base GenBank (http://www.ncbi.nlm.nih.gov/genbank/).

\section{RESULTADOS E DISCUSSÃO}

Os resultados da qPCR realizada com as diluições seriadas das amostras das três cepas padrão estão na figura 1. Para $C$. parapsilosis ocorreu amplificação em todas as amostras, mostrando sensibilidade até a diluição 1/4096. O Ct foi de 15,6 para a amostra inicial (não diluída), 17,5 para 1/8, 22 para 1/64, 26,6 para 1/512 e 30,7 para 1/4096. A temperatura de melting $(\mathrm{Tm})$ média foi de $78,8 \pm 0,28^{\circ} \mathrm{C}$, muito semelhante à Tm teórica $\left(79^{\circ} \mathrm{C}\right)$ gerada no software uMelt ${ }^{\mathrm{SM}}$ (https://dna.utah.edu/umelt/umelt.html). Ao analisar esses valores e as curvas de melting, verificou-se que nessa espécie possivelmente ocorreu amplificação da sequência alvo, pois há picos bem definidos para todas as amostras. Além disso, os primers apresentaram alta sensibilidade, o que de acordo com Hsu et al. (2003) é muito importante, pois infecções fúngicas apresentam uma carga patogênica baixa, sendo necessária a realização de ensaios que possuam sensibilidade aumentada.

Entretanto, a curva de eficiência da reação com cinco pontos de diluição $(1 ; 1 / 8$; $1 / 64 ; 1 / 512 ; 1 / 4096$ ) foi de apenas $67 \%$ (figura 2 ), um pouco abaixo dos valores ideais (90\% $\leq 100 \%$ ). De acordo com Taylor et al. (2010) isso sugere que pode haver algum inibidor da Taq DNA polimerase possivelmente oriundo de uma extração não adequada, primers com desenhos inapropriados, amplicons com estruturas secundárias ou, ainda, pode ocorrer por temperaturas inadequadas de anelamento. 
Figura 1 - Curvas de amplificação e de melting de C. albicans (azul), C. glabrata (verde) e C. parapsilosis (vermelho); na coluna da direita, as curvas de melting teóricas
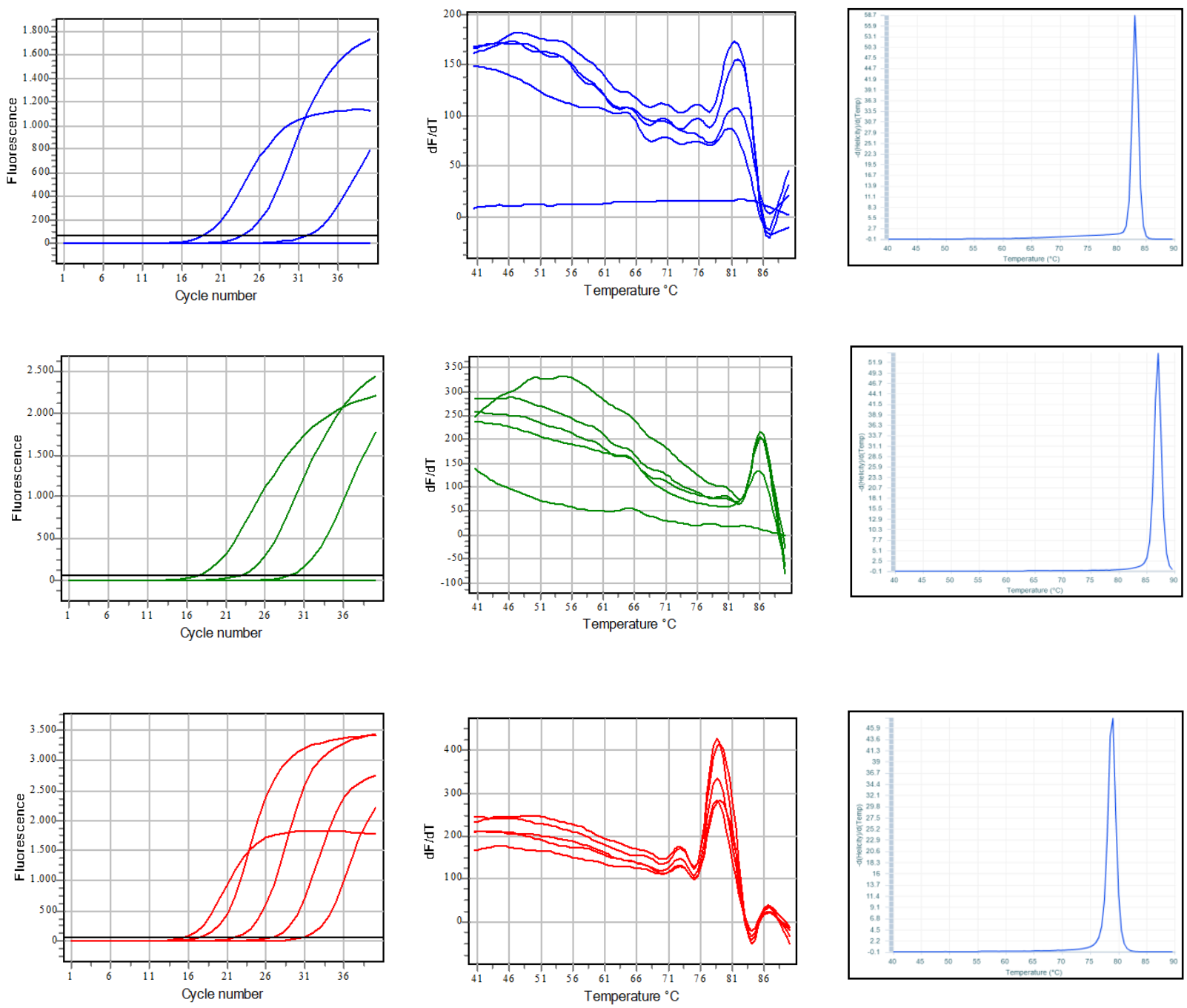

Figura 2 - Curva de eficiência da reação de $C$. parapsilosis

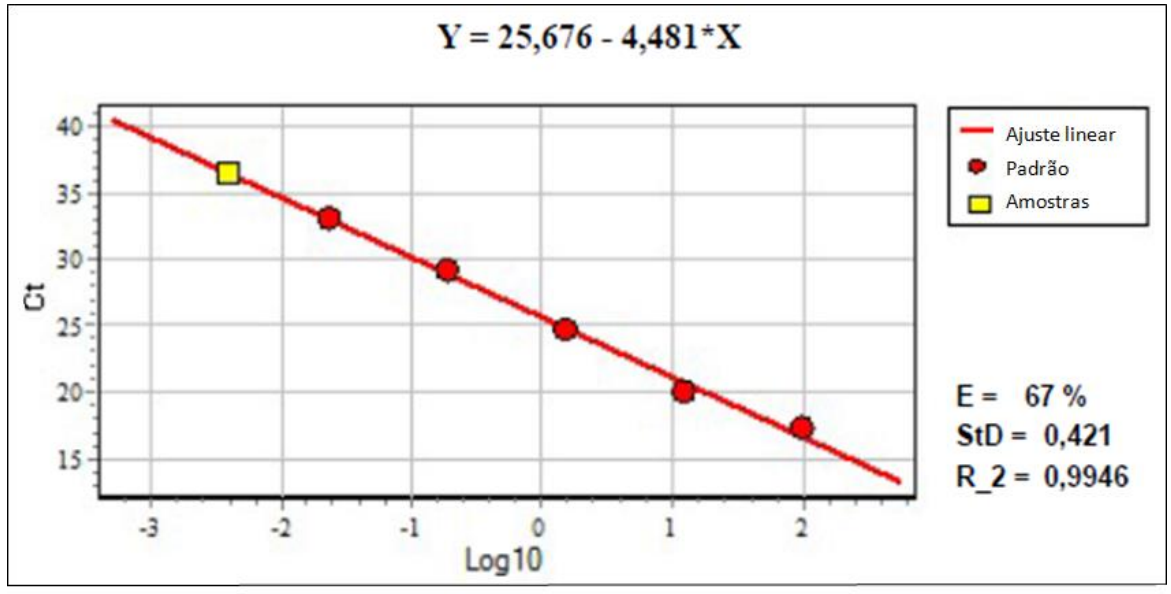

Legenda: E - Eficiência; StD - Desvio padrão; R_2 - Coeficiente de determinação 
Em relação às amostras de $C$. albicans a amplificação ocorreu apenas nas diluições 1/8 $(\mathrm{Ct}=18,6), 1 / 64(\mathrm{Ct}=23,6)$ e 1/512 $(\mathrm{Ct}=31,8)$. A $\mathrm{Tm}$ média reconhecida pelo equipamento de amplificação foi de $47,1 \pm 0,84^{\circ} \mathrm{C}$, muito diferente da teórica $\left(83^{\circ} \mathrm{C}\right)$. No entanto, ao examinar as curvas de melting, foi possível perceber picos definidos para cada amostra próximos à temperatura teórica esperada. Verificou-se também diversos picos menores (resultado de dimerização de primers e formação de produtos inespecíficos) que contribuem para que a Tm calculada pelo software tenha sido muito baixa (Figura 1).

Para C. glabrata também ocorreu amplificação apenas nas diluições $1 / 8(\mathrm{Ct}=17,4)$, 1/64 $(\mathrm{Ct}=22,8)$ e 1/512 $(\mathrm{Ct}=29,1)$. Assim como em $C$. albicans, a $\mathrm{Tm}$ média foi baixa $\left(50,45 \pm 6,01^{\circ} \mathrm{C}\right)$, diferindo muito da teórica $\left(87^{\circ} \mathrm{C}\right)$, o que pode ser explicado também pela formação de produtos inespecíficos nas reações (Figura 1).

Devido aos resultados inconsistentes, foi realizada uma análise in silico conforme as recomendações de Bustin et al. (2009). De acordo com a pesquisa nenhum dos conjuntos de primers se mostrou 100\% específico (Tabela 2). Analisando a Tabela 2 verificou-se que ocorrem alinhamentos inespecíficos, sendo que os principais foram com os primers de $C$. parapsilosis, pois podem anelar também em 4 cepas diferentes de $C$. albicans, que é a espécie mais prevalente em amostras clínicas.

Tabela 2 - Análise in silico da especificidade dos primers

\begin{tabular}{|c|c|c|}
\hline Espécie & Sequências específicas & Sequências não específicas \\
\hline C. albicans & $\begin{array}{l}965 \text { sequências de cepas } \\
\text { diferentes de } C \text {. albicans }\end{array}$ & 31 sequências \\
\hline C. glabrata & $\begin{array}{l}276 \text { sequências de cepas } \\
\text { diferentes de } C \text {. glabrata }\end{array}$ & $\begin{array}{l}27 \text { sequências, incluindo } \\
1 \text { sequência de } C \text {. albicans }\end{array}$ \\
\hline C. parapsilosis & $\begin{array}{c}728 \text { sequências de cepas } \\
\text { diferentes de } C \text {. parapsilosis } \\
\text { (contabilizado conjuntamente } \\
\text { as espécies } C \text {. metapsilosis e } \\
\text { C. orthopsilosis) }\end{array}$ & $\begin{array}{c}102 \text { sequências, incluindo } 2 \\
\text { sequências de } C \text {. } \\
\text { hyderabadensis, } \\
1 \text { sequência de } C \text {. tropicalis, } \\
4 \text { sequências de } C \text {. albicans e } \\
1 \text { sequência de } C \text {. } \\
\text { multigemmis }\end{array}$ \\
\hline
\end{tabular}


Ainda, as curvas de melting teóricas dos amplicons de C. albicans gerados pelos primers de C. parapsilosis possuem as mesmas Tm que os amplicons específicos (Tabela 3). Caso essa amplificação inespecífica ocorra, pode não ser possível distinguir entre as duas espécies se não estiver sendo utilizada a sonda espécie-específica. Entretanto, a tecnologia de SybrGreen ${ }^{\circledR}$ que utiliza a curva de dissociação de alta resolução (high resolution melting HRM) também pode ser uma alternativa, pois permite distinguir um único par de nucleotídeos pareados que diferencie duas sequências.

\section{Tabela 3 - Sequências dos amplicons}

\section{Espécie}

Sequência do amplicon

GGGTTTGCTTGAAAGACGGTAGTGGTA

AGGCGGGATCGCTTTGACAATGGCTTA

C. albicans GGTCTAACCAAAAACATTGCTTGCGGC GGTAACGTCCACCACGTATATCTTCAA (gb HQ876043.1)

TTTCTCCTGCCTGCGCTTAAGTGCGCG

C. glabrata GTTGGTGGGTGTTCTGCAGTGGGGGGA GGGAGCTGACAAAGACCTGGGAGTGT GCGT (gb JN093145.1)

GGGTTTGGTGTTGAGCGATACGCTGGG TTTGCTTGAAAGAAAGGCGGAGTATA AACTAATGGATAGGTTTTTTCCACTCA TTGGTACAAACTCC (gb JN831665.1)

C. parapsilosis

\section{Tamanho Tm teórica}

$108 \mathrm{pb} \quad 83^{\circ} \mathrm{C}$

$84 \mathrm{pb} \quad 87^{\circ} \mathrm{C}$

$94 \mathrm{pb} \quad 79^{\circ} \mathrm{C}$

TTGGTCAAAC

Considerando os primers de C. glabrata, o alinhamento inespecífico com a cepa de C. albicans também produz um amplicon com a mesma Tm do amplicon específico (Tabela 2). Entretanto, cabe ressaltar que as análises de especificidade in silico apresentam limitações, pois nem sempre correspondem à realizada in vitro (HENRIQUES et al., 2012).

Além da análise de especificidade, também é essencial prever a formação de heterodímeros e hairpins, pois isso influencia diretamente na qualidade dos resultados da qPCR. As estruturas secundárias geradas a partir dos primers são analisadas de acordo com os valores de $\Delta \mathrm{G}$ (energia livre de Gibbs). Quanto mais negativos os valores de $\Delta \mathrm{G}$ maior será a energia necessária para quebrar as estruturas, e consequentemente maiores serão as chances de ocorrerem problemas no ensaio. De acordo com recomendações da Integrated DNA 
Technologies - IDT (http://www.idtdna.com/site), é preciso evitar que ocorra uma quantidade significativa de hetero-dímeros com valores de $\Delta \mathrm{G}$ mais negativos que $-9 \mathrm{kcal} / \mathrm{mol}$. Além dos hetero-dímeros, a formação de hairpins também deve ser evitada, pois podem ocasionar anelamento inespecífico dos primers.

Tabela 4 - Análise in silico de formação de hetero-dímeros e hairpins

\begin{tabular}{|c|c|c|c|c|}
\hline Espécie & Hetero-dímeros & $\begin{array}{c}\Delta G(\text { valor mais } \\
\text { negativo gerado) }\end{array}$ & Hairpins & $\begin{array}{c}\Delta G(\text { valor mais } \\
\text { negativo gerado) }\end{array}$ \\
\hline C. albicans & 14 & $-4,95 \mathrm{kcal} / \mathrm{mol}$ & $\begin{array}{l}\text { Senso - } 1 \\
\text { Antisenso - } 1\end{array}$ & $-2,85 \mathrm{kcal} / \mathrm{mol}$ \\
\hline C. glabrata & 10 & $-8,7 \mathrm{kcal} / \mathrm{mol}$ & $\begin{array}{l}\text { Senso - } 1 \\
\text { Antisenso - } 2\end{array}$ & $-0,52 \mathrm{kcal} / \mathrm{mol}$ \\
\hline C. parapsilosis & 14 & $-8,31 \mathrm{kcal} / \mathrm{mol}$ & $\begin{array}{l}\text { Senso - } 9 \\
\text { Antisenso - } 1\end{array}$ & $-2,35 \mathrm{kcal} / \mathrm{mol}$ \\
\hline
\end{tabular}

Conforme pode ser visto na tabela 4 , os primers utilizados no presente trabalho não apresentam problemas significativos de formação de estruturas secundárias, pois os valores de $\Delta \mathrm{G}$ são mais positivos que $-9 \mathrm{kcal} / \mathrm{mol}$. No caso de $C$. glabrata e $C$. parapsilosis há valores próximos de $-9 \mathrm{kcal} / \mathrm{mol}$, porém em cada caso é apenas um hetero-dímero que apresenta esse valor. Além disso, a complementariedade entre os primers não ocorre nas extremidades 3', o que impede a amplificação dos dímeros. Assim, apesar dos dois hetero-dímeros apresentarem valores mais negativos de $\Delta \mathrm{G}$, eles não representam um problema para a realização da qPCR.

Devido aos problemas encontrados nas análises anteriores foi realizada uma tentativa de otimização da qPCR testando diferentes concentrações de primers, cujos resultados estão na figura 3. Novamente, os melhores resultados das amplificações foram os de $C$. parapsilosis, com o Ct de 13,4 para $0,4 \mu \mathrm{M}$ de primers; 12,4 para $0,6 \mu \mathrm{M}$ e 11,8 para 0,8 $\mu \mathrm{M}$. A Tm média foi de $80,4 \pm 0,42^{\circ} \mathrm{C}$, valor semelhante ao gerado na qPCR anterior, e os picos da curva de melting para as três concentrações foram similares.

Para $C$. albicans não houve amplificação eficiente em nenhuma das concentrações de primers, sendo o Ct médio muito elevado $(30,9 \pm 1,55)$. Já as curvas de dissociação não foram reprodutíveis, com a Tm variando muito em cada uma das concentrações $\left(45,9^{\circ} \mathrm{C}\right.$ para $0,4 \mu \mathrm{M}$ 
de primer, $73,3^{\circ} \mathrm{C}$ para $0,6 \mu \mathrm{M}$ de e $83,1^{\circ} \mathrm{C}$ para $0,8 \mu \mathrm{M}$ ), além de apresentarem mais de um pico. Já as curvas de amplificação de $C$. glabrata não apresentaram o formato característico e o $\mathrm{Ct}$ médio foi muito baixo $(9,96 \pm 1,83)$. A Tm média foi de $86,73 \pm 0,21^{\circ} \mathrm{C}$, valor semelhante ao teórico $\left(87^{\circ} \mathrm{C}\right)$, entretanto ocorreram picos referentes a amplificações indefinidas e dímeros de primers, o que foi confirmado no gel de agarose (Figura 4).

Figura 3 - Curvas de amplificação e de melting (C. albicans - azul; $C$. glabrata - verde; C. parapsilosis - vermelho)
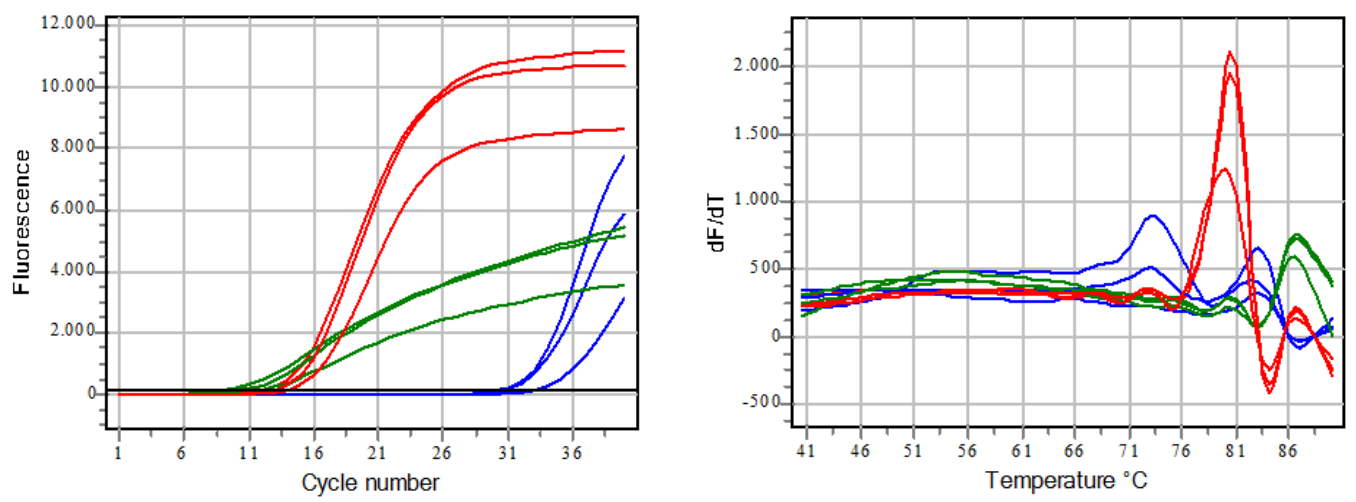

Figura 4 - Eletroforese em gel de agarose (amostras 1, 4 e 7 - 0,4 $\mu \mathrm{M}$ de primer; amostras 2, 5 e 8 - 0,6 $\mu \mathrm{M}$ de primer; amostras 3, 6 e 9-0,8 $\mu \mathrm{M}$ de primer)

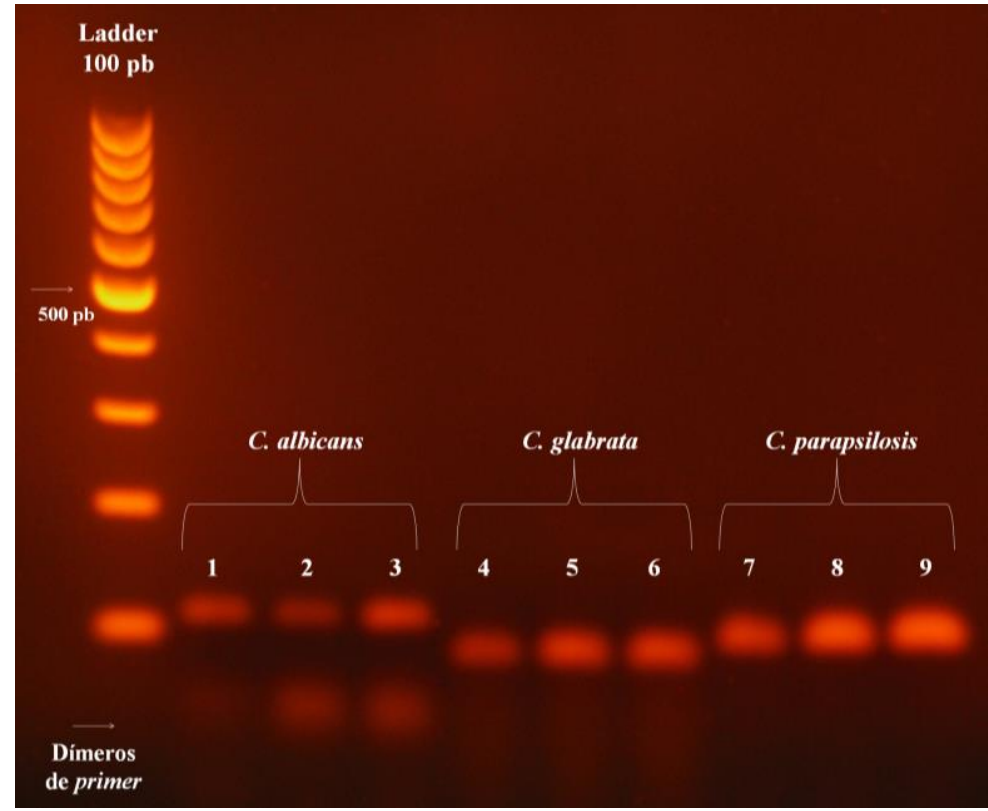

Se fossem analisados apenas os resultados gerados na qPCR poderia ser concluído que os primers de $C$. parapsilosis possuem a capacidade de identificar a espécie. Porém, com a análise in silico realizada, verificou-se que estes apresentam alguns problemas de especificidade, o que poderia gerar resultados falso-positivos. Assim, como citado 
anteriormente, deve ser usada conjuntamente uma sonda espécie-específica ou ser feita uma análise por HRM.

Para C. albicans e C. glabrata ocorreu a amplificação da sequência alvo, no entanto houve a formação de produtos secundários. Isso indica que podem existir falhas na construção dos primers, apesar de as análises in silico não terem mostrado formação de dímeros e hairpins significativos. Segundo Taylor e Mrkusich (2013) todos os primers devem ser validados antes de sua utilização, mesmo aqueles descritos na literatura e que apresentam análises in sillico favoráveis, pois diferentes tipos de amostras e de métodos de extração influenciam nos resultados. Considerando essas informações sugere-se que para a identificação dessas duas espécies sejam construídos novos primers. Contudo, Hsu et al. (2003), conseguiram identificar sete espécies de Candida (incluindo C. albicans, C. glabrata e C. parapsilosis) utilizando primers espécie-específicos e confirmando os resultados através da leitura das curvas de melting, demostrando que há possibilidade de identificação sem emprego de sondas.

No estudo de Zhang e Izadjoo (2015) foram identificadas cinco espécies de Candida, em amostras clínicas, baseando-se na técnica de fluoróforos intercalantes de fita dupla de DNA e utilizando um conjunto de primers universal, ou seja, com capacidade de discernir várias espécies do gênero, cujo anelamento ocorria na região ITS2, mesmo alvo de nosso estudo. Semelhante ao estudo de Hsu (2003), os autores diferenciaram as espécies pela análise das curvas de melting, sendo que esta metodologia demonstrou-se reprodutível entre as replicatas de uma mesma amostra.

As análises das curvas de dissociação também foram utilizadas no estudo de Bergman et al. (2007) como ferramenta de identificação/diferenciação de 14 espécies de Candida e de Cryptococcus neoformans (outra espécie de levedura patogênica) presentes em isolados de amostras clínicas, submetidas à qPCR com primers que alinham em diversas espécies do gênero nas regiões ITS1 e ITS2. Nesse estudo, as curvas de melting geradas após a amplificação das duas regiões foram interpretadas em conjunto.

Neste contexto, pode-se inferir que a identificação e diferenciação de espécies de Candida podem ser feitas sem o uso de sondas, uma vez que o uso dessas para detecção de uma grande quantidade de agentes fúngicos patogênicos é limitado, pois é espécie-específica, além de gerarem resultados falso-negativos quando construídas de forma inadequada (BERGMAN et al., 2007). Como alternativa à não utilização de sondas pode-se explorar o uso de primers de amplo espectro que geram amplicons com curvas de melting diferentes, os 
quais devem ser eficientes, sensíveis, específicos (para o gênero, por exemplo) e devem ser testados exaustivamente antes de sua aplicação para diagnóstico clínico.

\section{CONCLUSÃO}

De acordo com os resultados obtidos, conclui-se que a utilização de qPCR com fluoróforos intercalantes de DNA dupla fita e primers espécie-específicos é uma alternativa viável para identificação de espécies de Candida provenientes de cepas padrão, uma vez que ocorreu amplificação das espécies testadas, principalmente de C. parapsilosis. No entanto, cabe ressaltar que novos estudos são necessários a fim de sintetizar e testar primers com maior sensibilidade e especificidade para as espécies patogênicas. Além disso, serão necessárias investigações sobre a eficiência desses iniciadores em amostras clínicas, uma vez que tais amostras abrigam uma microbiota diversificada. Outra etapa importante para a utilização da qPCR para diagnóstico de Candida spp. em amostras geniturinárias é estabelecer o limite entre a infecção e o que representa a microbiota natural, pois as técnicas de qPCR, devido à sua característica de amplificação do material genético, podem detectar concentrações muito baixas do agente patogênico.

Ao final do presente trabalho conclui-se também que os estudos envolvendo qPCR são complexos e que para desenvolvê-los é necessário um planejamento prévio. Para esse planejamento não basta apenas seguir os protocolos descritos na literatura, mas sim, devem ser feitas buscas em bancos de dados para confirmação das sequências que serão analisadas, análises in silico dos primers e escolha de reagentes adequados. Posteriormente deve ser realizada a otimização das reações, além de desenvolver o conhecimento teórico e prático para a interpretação correta dos resultados.

\section{REFERÊNCIAS}

ANVISA, Agência Nacional de Vigilância Sanitária. Detecção e Identificação de Fungos de importância Médica. Disponível em: <http://www.anvisa.gov.br/servicosaude/microbiologia/mod_7_2004.pdf>. Acesso em: 23 fev. 2016.

BARNETT, J. A; A history of research on yeasts 8: taxonomy. Yeast, n. 24, p. 1141-1193, 2004. 
BERGMAN, A. et al. Rapid identification of pathogenic yeast isolates by real-time PCR and two-dimensional melting-point analysis. European Journal of Clinical Microbiology \& Infectious Diseases, n. 11, v. 26, p. 813-818, 2007.

BURKE, D.; DAWSON, D.; STEARNS, T. Methods in Yeast Genetics: a Cold Spring Harbour Laboratory Course Manual. New York: Cold Spring Harbour Laboratory Press, 2000.

BUSTIN, S. A. et al. The MIQE guidelines: minimum information for publication of quantitative real-time PCR experiments. Clinical Chemistry, n. 4, v. 55, p. 611-622, 2009.

CDC, Centers of Disease Control and Prevention. Fungal Diseases: Candidiasis. Disponível em: <http://www.cdc.gov/fungal/diseases/candidiasis/index.html>. Acesso em: 23 fev. 2016a.

CDC, Centers of Disease Control and Prevention. Fungal Disease: Symptoms of Genital/ Vulvovaginal Candidiasis. Disponível em: <http://www.cdc.gov/fungal/diseases/candidiasis/genital/symptoms.html>. Acesso em: 23 fev. 2016b.

DWIGHT, Z.; PALAIS, R,; WITTWER, C. T. uMELT: prediction of high-resolution melting curves and dynamic melting profiles of PCR products in a rich web application. Bioinformatics, n. 7, v. 27, p. 1019-1020, 2011.

FISHER, J. F. et al. Candida Urinary Tract Infection: Pathogenesis. Clinical Infectious Diseases, n. 6, v. 52, p. S437-S451, 2011.

GUIVER, M.; LEVI, K.; OPPENHEIM, B. A. Rapid identification of Candida species by TaqMan PCR. Journal Clinical Pathology. n. 5, v. 54, p. 362-366, maio.2001.

GUZEL, A. B. et al. Evaluation of risk factors in patients with vulvovaginal candidiasis and the value of chromID Candida agar versus CHROMagar Candida for recovery and presumptive identification of vaginal yeast species. Medical Mycology. n. 1, v. 49, p. 16-25, 2011.

HENRIQUES, A. et al. In silico vs in vitro analysis of primer specificity for the detection of Gardnerella vaginalis, Atopobium vaginae and Lactobacillus spp. BMC Research Notes, n. 1, v. 5, p. 637, 2012.

HORVATH, L. L et al. Direct isolation of Candida spp. from Blood Cultures on the Chromogenic Medium CHROMagar Candida. Journal of Clinical Microbiology, n. 6, v. 41, p. 2629-2632, jun.2003.

HSU, M.-C. et al. Species identification of medically important fungi by use of real-time LightCycler PCR. Journal of Medical Microbiology, n. 12, v. 52, p. 1071-1076, 2003.

KOŁACZKOWSKA, A; KOŁACZKOWSKI, M. Drug resistance mechanisms and their regulation in non-albicans Candida species. Journal of Antimicrobial Chemotherapy, p. dkv445, jan.2016. 
KWEON, O. J. et al. Performance evaluation of a DNA chip assay in the identification of major genitourinary pathogens. Journal Of Microbiological Methods. v. 109, p. 117-122, 2015.

LUTZ, B. S. et al. Padronização das técnicas de PCR convencional e PCR em tempo real para diagnóstico de Candida albicans. Revista Jovens Pesquisadores, n. 1, v. 3, 2013.

MYCOBANK.

$<$ http://www.mycobank.org/BioloMICS.aspx?Table=Mycobank\&Rec=56219\&Fields=All $>$. Acesso em: 23 fev. 2016.

NEMCOVA, E. et al. Rapid Identification of Medically Important Candida Isolates Using High Resolution Melting Analysis. PloS One, n. 2, v. 10, p. e0116940, fev.2015.

ODDS, F. C.; BERNAERTS, R. CHROMagar Candida, a new differential isolation medium for presumptive identification of clinically important Candida species. Journal of Clinical Microbiology, n. 8, v. 32, p. 1923-1929, ago.1994.

OGATA, K. et al. Sensitive and rapid RT-qPCR quantification of pathogenic Candida species in human blood. Journal of Microbiological Methods, v. 117, p. 128-135, out.2015.

OZCAN, K. et al. Performance of Chromogenic Candida Agar and CHROMagar Candida in recovery and presumptive identification of monofungal and polyfungal vaginal isolates. Medical Mycology. n.1, v. 48, p. 29-34, 2010.

PAPAS, P. G. et al. Clinical practice guidelines for the management of candidiasis: 2009 update by the Infectious Diseases Society of America. Clinical Infectious Diseases. n. 5, v. 48, p. 503-535, 2009.

SKINNER, C. E.; FLETCHER, D. W. A review of the genus Candida. Bacteriology Reviews, n. 4, v. 24, p. 397-416, dez.1960.

TAYLOR, S. et al. A practical approach to RT-qPCR - publishing data that conform to the MIQE guidelines. Methods, n. 4, v. 50, p. S1-S5, 2010.

TAYLOR, S. C.; MRKUSICH, E. M. The state of RT-quantitative PCR: Firsthand Observations of Implementation of Minimum Information for the Publication of Quantitative Real-Time PCR Experiments (MIQE). Journal of molecular microbiology and biotechnology, n. 1, v. 24, p. 46-52, 2013.

THAN, L. T. L. et al. Detection of Medically Important Candida Species by Absolute Quantitation Real-Time Polymerase Chain Reaction. Jundishapur Journal of Microbiology, n. 1, v. 8, p. e-14940, 2015.

ZHANG, B.; IZADJOO, M. Differential Diagnosis of Candida Species With Real-Time Polymerase Chain Reaction and Melting Temperature Analyses (RTPCR-MTA). Military Medicine, n. 6, v. 180, p. 652-659, jun.2015. 


\section{Como citar este documento:}

KOEHLER, Alessandra et al. Identificação de três espécies de Candida por PCR em tempo real. Revista Jovens Pesquisadores, Santa Cruz do Sul, v. 6, n. 1, jun. 2016. ISSN 2237-048X. Disponível em: <https://online.unisc.br/seer/index.php/jovenspesquisadores/article/view/7341>. Acesso em:... doi:http://dx.doi.org/10.17058/rjp.v6i1.7341. 